\title{
ESTÁGIO CURRICULAR SUPERVISIONADO: PERCEPÇÕES DO ALUNO-TERAPÊUTA EM FONOAUDIOLOGIA NO ÂMBITO HOSPITALAR
}

\section{Curricular supervised traineeship: perceptions of student-therapist in Speech, Language and Hearing Sciences in a hospital}

\author{
Moisés Andrade dos Santos de Queiroz (1), Camila Lima Verde Teixeira ${ }^{(2)}$, Cleiciane Martins Braga ${ }^{(3)}$, \\ Kelly Alves de Almeida ${ }^{(4)}$, Rakel Ximenes Pessoa ${ }^{(5)}$, Rita de Cássia Araújo Almeida ${ }^{(6)}$, \\ Thamyris Marron de Mesquita ${ }^{(7)}$, Maria Cláudia Mendes Caminha Muniz ${ }^{(8)}$
}

\begin{abstract}
RESUMO
Objetivo: construir uma descrição da percepção dos estagiários do curso de fonoaudiologia em leito hospitalar. Método: pesquisa realizada durante a disciplina de Estágio Supervisionado II em Fonoaudiologia do último semestre do Curso de Graduação em Fonoaudiologia da Universidade de Fortaleza no período de fevereiro a junho de 2010. Optou-se por uma abordagem qualitativa registrando-se, por parte dos estagiários-pesquisadores, suas impressões pessoais, por meio da construção de diários e notas de campo, no atendimento a pacientes neurogênicos à beira do leito. Resultados: as categorias encontradas dividiram-se em: ansiedade e frustração; insegurança e incapacidade; angústia, tristeza e medo; empoderamento profissional; empatia e lembranças e; sentimentos negativos. Os sentimentos ressaltaram o medo de intervir com o paciente. Porém, a rotina faz o estagiário mais seguro quanto aos seus procedimentos e, com o tempo, é possível controlar os sentimentos em relação às medidas a serem tomadas junto ao paciente. Conclusão: concluiu-se que as percepções referidas pelos estagiários estão diretamente relacionadas ao impacto emocional inicial. A falta da vivência interfere na atuação, fazendo o aluno buscar o apoio do docente. É pela experiência que o estagiário adquire conhecimento técnico-prático, proporcionando uma reflexão crítica que o leva à autoconfiança. A importância de levar o aluno ao pensamento crítico-reflexivo torna-o um profissional consciente de seu papel na sociedade, possibilitando a um atendimento mais humanizado e diferenciado implicando em uma melhora na qualidade de atendimento do paciente debilitado.
\end{abstract}

DESCRITORES: Diários; Estudantes de Ciências da Saúde; Fonoaudiologia

(1) Fonoaudiólogo; Mestrando em Ciências Médicas pela Universidade Federal do Ceará, UFC, Fortaleza, Ceará, Brasil.

(2) Fonoaudióloga graduada pela Universidade de Fortaleza, UNIFOR, Fortaleza, Ceará, Brasil.

(3) Fonoaudióloga graduada pela Universidade de Fortaleza, UNIFOR, Fortaleza, Ceará, Brasil.

(4) Fonoaudióloga; Mestranda em Saúde Coletiva pela Universidade Federal de Mato Grosso, UFMT, Cuiabá, Mato Grosso, Brasil.

(5) Fonoaudióloga graduada pela Universidade de Fortaleza, UNIFOR, Fortaleza, Ceará, Brasil.

(6) Fonoaudióloga graduada pela Universidade de Fortaleza, UNIFOR, Fortaleza, Ceará, Brasil.

(7) Fonoaudióloga graduada pela Universidade de Fortaleza, UNIFOR, Fortaleza, Ceará, Brasil.

\section{INTRODUÇÃO}

É recente a atuação do fonoaudiólogo nos hospitais. Sua inserção, especificamente nas unidades de terapia intensiva (UTI), teve início com a demanda de pacientes com transtornos da deglutição decorrente desordens neurológicas e, posteriormente, com a conquista de um espaço nas

(8) Fonoaudióloga; Professora Assistente do curso de Fonoaudiologia da Universidade de Fortaleza, UNIFOR; Mestre em Saúde Coletiva pela Universidade de Fortaleza, UNIFOR, Fortaleza, Ceará, Brasil.

Conflito de interesses: inexistente 
demais unidades de atendimento aos pacientes com distúrbios de linguagem, traumas faciais, queimaduras e disfagias mecânicas ${ }^{1}$.

Com o crescimento do mercado de trabalho na área hospitalar, os currículos oferecidos pelos cursos de graduação em fonoaudiologia vêm estabelecendo disciplinas teóricas, acerca da fonoaudiologia hospitalar nas visões biológica e humanista; e práticas, onde o acadêmico tem a oportunidade de desenvolver todo o atendimento fonoaudiológico ao paciente hospitalizado, prestando cuidado individualizado de acordo com as necessidades básicas de saúde biopsicossocial.

Para que isto ocorra, torna-se indispensável à parceria da universidade com os serviços de saúde e a comunidade, possibilitando a inserção do acadêmico no cotidiano de trabalho para um desempenho produtivo e consistente. A partir deste princípio, surge o estágio curricular supervisionado em fonoaudiologia hospitalar, que oportuniza uma vivência relevante ao acadêmico devido à autonomia e à interação que este experiencia, em sua intervenção no processo saúde-doença, com os diferentes atores sociais ${ }^{2}$.

A complexidade do estágio curricular supervisionado ocorre quando, o aluno, que adquiriu um conteúdo teórico específico, utiliza este conhecimento para a resolução dos problemas da população atendida. Nesta etapa, o acadêmico desenvolve competências técnicas e humanísticas para o exercício da profissão, por meio das orientações e feedback, de um docente ou supervisor, acerca do seu desenvolvimento profissional e educacional, objetivando o realizar de um atendimento adequado; o ampliar do seu conhecimento teórico-prático; e o formar de um profissional crítico e reflexivo, capaz de atuar dentro do cenário experenciado, apto às demandas sociais ${ }^{3}$.

O ambiente de estágio no âmbito hospitalar trás preocupações adicionais às avaliações curriculares, pois o acadêmico deve contribuir no atendimento à pacientes acamados que merecem cuidados, compreensão e respeito ${ }^{4}$. Em adição, o hospital é considerado um ambiente estressante tanto para o paciente, quanto para a própria equipe que nele atua ${ }^{5}$.

Estudos que avaliaram acadêmicos da área da saúde sugerem a existência de uma relação entre a escolha e o desempenho profissional com as características pessoais do indivíduo ${ }^{6,7}$. Entre as características essenciais ao âmbito hospitalar, sugere-se: o autocontrole emocional, as relações interpessoais, a habilidade de trabalhar em equipe e a consciência humanística ${ }^{6,8}$.

Na literatura fonoaudiológica, há uma escassez no conhecimento psicológico dos acadêmicos dentro do estágio curricular supervisionado hospitalar. Pouco se discute a respeito do que o indivíduo pensa, sabe, conhece e espera desta experiência. Estudos referem que o estágio curricular supervisionado pode ser uma experiência rica no ponto de vista clínico, porém é fragmentada e pontual, onde os acadêmicos não buscam identificar suas limitações e sentimentos, devido à ausência de vínculos sólidos e pequena duração oferecida, o que leva ao indivíduo a pensar em seu próprio benefício do que no impacto da atuação na melhora do paciente? ${ }^{7}$.

Diante do exposto, pretende-se com este estudo construir uma descrição da percepção dos estagiários do curso de fonoaudiologia, tendo como base sua inserção e vivência junto à prática em leito hospitalar, baseando-se em suas reflexões no que concerne às experiências na constituição do eu, da formação e (trans)formação nas práticas em saúde, sociais e interculturais e, entre os espaços e aprendizagens, bem como os territórios da formação humana.

\section{MÉTODO}

O presente trabalho foi realizado durante a disciplina de Estágio Supervisionado II em Fonoaudiologia do último semestre do Curso de Graduação em Fonoaudiologia da Universidade de Fortaleza UNIFOR, na cidade de Fortaleza, Ceará, no período de fevereiro a junho de 2010.

Optou-se por uma abordagem qualitativa de pesquisa, baseada em Minayo $^{9}$, registrando-se inicialmente, por parte dos estagiários-pesquisadores, suas impressões pessoais, dentre valores, opiniões, representações, crenças e outras categorias que implicam fenômenos complexos e subjetivos nas ações em saúde, mais especificamente, no atendimento junto à pacientes neurogênicos a beira do leito. Tais impressões foram coletadas a partir de suas práticas durante o estágio curricular supervisionado em uma instituição hospitalar pública municipal de referência terciária e abrangência Estadual e Municipal.

Foram utilizados como instrumentos de coleta de dados o diário e notas de campo realizados durante o período de estágio curricular supervisionado de sete alunos do curso de fonoaudiologia, etapa esta seguida pela análise cultural dos dados colhidos. A partir da análise dos diários e notas de campo, os dados foram categorizados, analisados e confrontados com a literatura encontrada.

Paralelamente foi realizada uma revisão de literatura ancorada em pesquisa utilizando os termos: recursos humanos em saúde, pesquisa qualitativa, educação profissional em saúde, ensino-aprendizagem e estágio curricular nos bancos de dados do 
Scielo, Google e Google acadêmico, acrescentando uma revisão não sistemática de sites na internet.

\section{RESULTADOS}

Após leitura dos relatos dos diários de campo, os mesmos foram organizados em categorias e subcategorias, de acordo com as impressões de cada aluno.

As categorias encontradas dividiram-se em: ansiedade e frustração; insegurança e incapacidade; angústia, tristeza e medo; empoderamento profissional; empatia e lembranças e; sentimentos negativos.

Alguns alunos, em sua experiência inicial de estágio curricular supervisionado, expressaram sentimentos de ansiedade em relação aos procedimentos técnicos e no relacionamento com o paciente e o docente.

\section{CATEGORIAS E SUBCATEGORIAS}

\section{Ansiedade e frustração}

\subsection{Pressa para agir - $o$ atendimento}

A ansiedade do aluno leva a pressa para chegar ao leito, conhecer e realizar procedimentos técnicos junto o paciente.

"Muita ansiedade, vontade de chegar logo no hospital para poder conhecer como era a realidade de lá." (ALUNO 7) (comentário 1) "Acho que estava tão ansioso que não queria saber da história do paciente, só me interessava ver qual o acidente que ele sofreu e como ele estava no dia atual, e então, ir direto ao leito para saber mais por lá mesmo. Eu sei que isto não é o correto, e como eu disse, fui ansioso." (ALUNO 4) (comentário 2)

\subsection{Sensação de incapacidade frente à} necessidade do paciente

A ansiedade e a insegurança também foram referidas na realização dos procedimentos, principalmente durante o primeiro contato com os pacientes e pelo medo da não aceitação por estes.

"Mas eu lembro que fiquei meio frustrado por ver que eles estavam tão acometidos que não podiam fazer "nada". Mas desse "nada" que eu fiz, eu ainda gostei." (ALUNO 4) (comentário 3)

"Me senti um pouco desmotivada, pois a acompanhante parecia não ter interesse no que era passado, parecia que tudo aquilo que eu estava falando não ia surtir efeito, tentei acordar o paciente, mas não foi possível." (ALUNO 1) (comentário 4)
“(...) não me sinto preparada emocionalmente para enfrentar certas situações vividas no hospital, no leito hospitalar." (ALUNO 3) (comentário 5)

\subsection{Impotência do profissional}

Foi considerado que o relacionamento do estagiário de fonoaudiologia com a equipe médica é restrito, pois não há na instituição, ainda, a vivência que possibilite este contato com os médicos e os demais profissionais da saúde.

"Na hora que chegamos no posto de enfermagem pedimos um canudo a enfermeira disse que não tinha, e nem tinha como conseguir" (ALUNO 2) (comentário 6)

\section{Insegurança e incapacidade}

\subsection{A presença do desconhecido}

O estagiário enfrenta uma série de dificuldades no início do estágio curricular supervisionado, como o fato de tocar uma pessoa desconhecida.

"... A sensação que tive foi de muito medo, não conseguia entrar no leito, foi preciso a professora entrar comigo, me "empurrar" até o paciente. E não consegui também ter uma conversa com eles..." (ALUNO 2) (comentário 7)

“... Senti-me insegura em relação ao meu desempenho junto aos pacientes, nunca tinha entrado em hospital, então pra mim aquilo foi um choque..." (ALUNO 2) (comentário 8)

\subsection{A experiência faz falta...}

Os estagiários enfatizaram o medo de errar, o que pode estar relacionado à falta de vivência.

“... Não tinha experiência nenhuma, não sabia como funcionava a vida hospitalar, mais sabia que ia ver muitos casos de doenças, mas também não sabia como ia agir, pois não tinha visto nada na teoria..." (ALUNO 2) (comentário 9)

“... Não que eu não goste de linguagem, eu adoro afasias, mas apesar de adorar eu sei que não sou bom nessa área porque me falta muito estudo." (ALUNO 4) (comentário 10)

\subsection{O desempenho pessoal junto ao paciente $e$} perante os colegas

Ao se deparar com a responsabilidade da atuação profissional, o estagiário buscou o amparo, a atuação "protegida", ou seja, supervisionada.

“... eu não consigo ser desenvolto em um local que não esteja apenas eu e o paciente, e eles precisam de algo que eu não con- 
seguia oferecer, que era isto." (ALUNO 4) (comentário 11)

“... o sentimento de incapacidade também surgiu, a vontade de reverter o quadro dos pacientes e evitar o seu sofrimento, ao mesmo tempo, senti a vontade e a necessidade de ficar conversando com eles e seus acompanhantes pra, de certa forma, os confortar, dar uma palavra amiga, de apoio, mas me senti envergonhada diante dos meus colegas..." (ALUNO 3) (comentário 12)

\section{Angústia, tristeza e medo}

3.1 Situação do paciente

A maioria dos estagiários manifestou os sentimentos de tristeza, angústia e medo, que podem ser causados pelo fato do aluno estar lidando com algo novo e desconhecido, isto é, o primeiro contato com o paciente.

"Me deu pena, tristeza, mas tentei não passar pro paciente o que eu estava sentindo." (ALUNO 2) (comentário 13)

"O primeiro dia de atendimento me deixou triste por eu não gostar de ver pessoas em hospital passando por algum tipo de sofrimento." (ALUNO 3) (comentário 14)

"Na hora que cheguei ao hospital, senti aquele clima de tristeza das pessoas." (ALUNO 5) (comentário 15)

\subsection{A vida é um jogo: pode acontecer comigo!}

O contato com a realidade desconhecida do ambiente hospitalar levou aos estagiários a colocarem-se no lugar do paciente e sua família.

"... isso me deu uma angústia, pensei que pode acontecer com qualquer um de nós!" (ALUNO 5) (comentário 16)

“... nervosa com o que eu poderia encontrar de início pensava na patologia que eu poderia me deparar, queria algo que me sentisse a vontade em atender, que não envolvesse tanto contato "pele a pele"." (ALUNO 1) (comentário 17)

\subsection{O sofrimento e a solidão}

Os sentimentos afluem quando o estagiário inicia a escrita do diário de campo e entra em contato com suas percepções. Esses sentimentos são importantes para que se tenha uma reflexão crítica da sua atuação atual, da realidade e futura profissão.

"Apareceram sentimentos de medo, pena, nervosismo, incapacidade, insegurança e até mesmo o receio de ter que fazer limpeza oral em um paciente." (ALUNO 3) (comentário 18)
"A sudorese tomou conta do meu corpo. Me senti em uma sauna, mão gelada e face demonstrando medo e pena. Tentei interagir com o paciente mais não obtive sucesso o que me deixou mais incomodada por ele não conseguir se comunicar." (ALUNO 3) (comentário 19)

"Nesse momento minha cabeça se enchia de pergunta, dúvidas e muito medo passava pela minha cabeça." (ALUNO 5) (comentário 20)

“...sentir-me um pouco angustiada, pois naquele momento não podia ajudar em muita coisa, mas conseguir conter a emoção fui confiante durante as orientações passada para a mãe." (ALUNO 1) (comentário 21)

"Ela estava acordada, com um olhar fixo para o teto, e foi nesse momento que todos os meus sentimentos vieram à tona. Medo, insegurança, aflição, pena, angústia." (ALUNO 5) (comentário 22)

\section{Empoderamento profissional}

\subsection{Identificação profissional}

Com esse estudo, verificou-se que apenas três estagiários referiram identificar-se com ambiente hospitalar.

"(...) sempre tive vontade de atuar na área hospitalar." (ALUNO 1) (comentário 23)

"Eu sempre esperei por essa disciplina, porque é a área que almejo trabalhar." (ALUNO 4) (comentário 24)

“(...) A sensação que tive foi de muita alegria pela confirmação de que estava certa quanto a minha escolha profissional." (ALUNO 6) (comentário 25)

\subsection{Reconhecimento da importância da} profissão

Foi identificado pelos estagiários a necessidade da atuação fonoaudiológica junto aos pacientes hospitalizados e a procura do serviço fonoaudiológico pelos demais profissionais.

“(...) Percebi a importância do nosso trabaIho fonoaudiológico diante dessas pessoas"; (ALUNO 3) (comentário 26)

“(...) senti muito a importância da minha profissão e o quanto os outros profissionais de saúde são leigos em relação ao trabalho fonoaudiológico" (ALUNO 5) (comentário 27)

“(...) passei a manhã imaginando como seria $o$ atendimento aos pacientes que tanto precisavam da nossa ajuda". (ALUNO 6) (comentário 28) 


\subsection{A Interdisciplinaridade funciona}

Sobre o tópico interdisciplinaridade, os estagiários perceberam o quanto esta é necessária:

"(...) foi proveitoso, pois teve interdisciplinaridade com maior resolutividade para o paciente." (ALUNO 1) (comentário 29)

"(...) a interação dos profissionais também é um fato importante, que não se consegue trabalhar se não for em conjunto, porque muitas vezes, para se realizar um procedimento, é necessário antes o procedimento do outro profissional." (ALUNO 3) (comentário 30)

\section{Empatia e lembranças}

\subsection{Reconhecer-se no outro}

Além disto, os estagiários relataram que o paciente que necessita de ajuda, muitas vezes não consegue diferenciar o profissional da saúde em sua especialidade, acreditando que todos estão aptos a tratar qualquer problema que ocorra.

"O paciente hospitalar não faz diferenciação da sua profissão com os demais encontrados pra eles somos profissionais da saúde, que qualquer um ali pode resolver seu problema." (ALUNO 5) (comentário 31)

"Saber que a vida da gente pode mudar em questão de segundos, que somos imortais e que ninguém deve se vangloriar dizendo ou pensando que isso só acontece com o próximo." (ALUNO 4) (comentário 32)

\subsection{Estar perto e estar longe da situação}

A forma de atendimento ao enfermo foi observada como crucial e, algumas vezes, com retorno gratificante. Os relatos demonstraram que o terapeuta deve agir com razão e emoção e compreendendo que está tratando seres humanos e não simples objetos.

"As vezes eu me sinto muito frio em relação à pessoa, principalmente quando eu me comparo com as outras alunas. Eu me sinto diferente delas e isso faz eu me sentir um pouco mal." (ALUNO 1) (comentário 33)

\subsection{Pequenos atos fazem a diferença}

Nos pequenos atos proporcionados pelos profissionais o paciente e a família muitas vezes se sentem empoderados e se tornam o diferencial no tratamento:

"Percebi a importância do nosso trabalho fonoaudiológico diante dessas pessoas, que muitas vezes um simples Boa tarde, um gesto, um olhar, pode trazer benefícios para eles, pode fazer a diferença no seu dia." (ALUNA 5) (comentário 34)
"A vontade que me dar é fazer algo por toda essa gente que precisa de cuidados, informações e medidas de prevenção que são capazes de fazer com que eles não cheguem a esse ponto de intervenção que são submetidos." (ALUNO 3) (comentário 35)

\section{Sentimentos negativos}

6.1 A situação do sistema de saúde pública

Não apenas motivações relacionadas ao salário, mas também, ao próprio ambiente em que o profissional irá atuar, foram observados no relato:

"Ao chegar ao hospital tive o aspecto de sujo, macas pelo corredor, elevadores antigos e muita gente esperando o atendimento. Fiquei assustada com o que presenciei, mas o pior estava por vir." (ALUNO 5) (comentário 36) "Ao chegar ao sexto andar do hospital, vi aquele corredor sombrio com aquelas pessoas deitadas nas macas dentro dos leitos, tão debilitadas, às vezes sozinhos, alguns por muito tempo no hospital. Fiquei chocada quando vi!" (ALUNO 7) (comentário 37) "Senti algo diferente, a movimentação de um andar para o outro, a maioria dos pacientes estavam em estado de alerta, porém com fraturas expostas, com bom nível de consciência, eles aparentavam sentir sufocados com tudo aquilo o calor sufocante" (ALUNO 1) (comentário 38)

\subsection{A humanização pela janela}

Observou-se que a falta de motivação ambiental e mesmo psicológica, pode levar à criação de profissionais "não humanizados". O atendimento do profissional pode ser afetado também pela relação que este possui com os familiares e/ou cuidadores.

"... não queria saber da história do paciente, só me interessava ver qual o acidente que ele sofreu e como ele estava no dia atual". (ALUNO 4) (comentário 39)

"Perguntamos se o paciente tinha engasgos, e ela disse que sim e com freqüência. Orientamos que não era seguro para o paciente ser alimentado naquela posição, porém ela não deu muita credibilidade para nós." (ALUNO 7) (comentário 40)

\section{DISCUSSÃO}

Os sentimentos percebidos de ansiedade e frustração pelos estagiários podem ser explicados pela entrada brusca dos mesmos numa situação desconhecida e pode ser um fator desencadeante de tensão e ansiedade, que interferem negativamente no aprendizado. Assim, torna-se imprescindível a 
presença de um docente consciente em campo de estágio que colabore e tenha atitudes de compreensão para com o estagiários ${ }^{10}$.

Os sentimentos de ansiedade descritos pelos alunos no primeiro contato com o paciente comprometem a sua atuação, bloqueando a ação de cuidar efetivamente do mesmo ${ }^{11}$.

A constante tensão vivida pelos estagiários, em relação ao que tem que ser feito para ajudar os pacientes e aquilo que conseguem realizar, leva-os a sentimentos de frustração e ansiedade ${ }^{11}$.

Diante das dificuldades para realizar os encaminhamentos necessários e das cobranças em diminuir o sofrimento e controlar os riscos de casos graves, o profissional da saúde que atua no ambiente hospitalar é submetido a um estresse crônico. Por conta disso, incumbe-lhes tomar decisões delicadas que mobilizam forte carga afetiva, uma vez que convivem com a angústia dos familiares, necessitando Ihes dar suporte em uma experiência emocional crítica, além de fazer adaptações radicais no processo de trabalho, quase sempre sob condições bastante precárias ${ }^{5}$.

Os aspectos relacionados à insegurança e a incapacidade podem ser percebidos pelos estagiários, quando estes sentem medo do desconhecido, diante da relação vivida entre o estagiário e o paciente, e nas descobertas do processo de cuidar no início da prática profissional. São aspectos considerados como algo novo, causando, portanto, ansiedade ${ }^{10}$.

A inabilidade em atuar com seus sentimentos e o dos pacientes e; a dificuldade para associar a teoria à prática, que são evidenciadas quando Ihe é cobrado um desempenho junto ao paciente ${ }^{12}$.

O estágio curricular supervisionado introduz o estagiário na prática, propiciando ao graduando experimentar sentimentos ambivalentes. Por um lado ele iniciará o estágio e irá sentir-se, pela primeira vez, inserido na profissão; por outro, ele experimentará a angústia relatada por colegas que já fizeram a disciplina ${ }^{10}$.

As dificuldades e as angústias que o estagiário vivencia no relacionamento com o paciente, 0 docente e o ambiente podem produzir efeitos positivos e negativos referentes às primeiras experiências práticas do estagiário junto aos pacientes ${ }^{10}$.

A partir destes fatos, o estagiário manifesta a necessidade de apoio das pessoas que lhes são próximas nesta vivência, como seu o colega de grupo ou o docente, a fim de que possa superar suas dificuldades ${ }^{12-13}$.

Considera-se que o aluno estabelece um relacionamento interpessoal tanto com o objeto de sua atuação, o paciente, quanto com o docente que lhe acompanha em campo. Acredita-se que as relações humanas são ricas de significações e contradições, e que se tornam fonte de conhecimento da realidade vivida ${ }^{12}$.

Diante dos sentimentos percebidos de angústia, tristeza e medo, entendeu-se que a sensação de tristeza manifestada pelos alunos em seus relatos demonstra que o lado sentimental não pode se desvincular do profissional. Colocar-se no lugar do paciente é praticar a humanização, tão valorizada no Sistema Único de Saúde (SUS) ${ }^{14}$.

No Brasil, os profissionais de saúde como fisioterapeutas, enfermeiros, fonoaudiólogos, médicos e terapeutas ocupacionais encontram-se em estado de insalubridade ocupacional que, consequentemente, atinge o emocional repercutindo na assistência oferecida ao paciente ou a si mesmo ${ }^{15}$.

O fato destes profissionais de saúde estar em contato constante com um local de prática que transmite sensações pessimistas, como amargura, angústia e frustrações, faz com que o profissional se coloque no lugar do paciente ${ }^{16-17}$.

O medo, a ansiedade e a angústia podem ser minimizados pela assistência do docente que acompanha o estagiário no momento do atendimento, demonstrando a importância da assistência emocional ao aluno de estágio curricular supervisionado em contato com o paciente ${ }^{18}$.

Em relação ao empoderamento profissional, o profissional que atua em instituições hospitalares está exposto a diversos fatores que afetam diretamente o seu bem estar. Dentre vários, podem-se citar as longas jornadas de trabalho, o número insuficiente de pessoal, a falta de reconhecimento profissional, a alta exposição do profissional a riscos químicos e físicos, assim como o contato constante com o sofrimento, a dor e muitas vezes a morte ${ }^{15}$.

O desempenho destes profissionais envolve uma série de atividades que necessitam forçadamente de um controle mental e emocional muito maior que em outras profissões ${ }^{19}$. Eles devem manejar os pacientes em estado grave e compartiIhar, com o enfermo e seus familiares, a angústia, a dor, a depressão e o medo de padecerem ${ }^{20,21}$.

Para tanto é necessário que haja notória identificação com a área de atuação de sua profissão6,7.

Tenta-se fortalecer a profissão e divulgar a importância da atuação do profissional nos diversos segmentos da sociedade ${ }^{16}$. O reconhecimento responde àqueles que querem provar o desmerecimento do profissional fonoaudiólogo na atuação hospitalar.

O trabalho em equipe na área da saúde distingue-se pela homogeneidade dos objetivos propostos. Assim, a equipe interdisciplinar, descrita como um grupo de profissionais de diversas formações atua de forma interdependente, interrelacionando-se 
num mesmo ambiente de trabalho, por intermédio de comunicações formais e informais, sendo imprescindível no atendimento hospitalar ${ }^{22}$.

A empatia e as lembranças podem ser observadas diante de situações estressantes, onde a equipe de saúde precisa considerar as necessidades da família. O estabelecimento do plano de cuidados à família deve ser construído por meio do diálogo e da busca dos significados que as experiências de doença geram em cada pessoa ${ }^{23}$.

A afetividade proporcionada aos familiares e ao paciente é fundamental para a recuperação deste, sendo a comunicação, sob suas diferentes formas, o principal meio para favorecer a interação entre a equipe de saúde, o paciente e os seus familiares ${ }^{24}$.

O profissional da saúde, muitas vezes, pode se colocar no lugar do paciente para compreender as suas angústias, medos, inseguranças e demais sentimentos. Isto contribui para uma maior segurança e desempenho profissional durante a intervenção, assim como para melhorar o vínculo familiar $^{25-26}$.

O profissional da saúde deve estar preparado para enfrentar os desafios do cotidiano, precisando agir com razão e emoção e compreendendo que está tratando seres humanos e não simples objetos.

Para compreender o ser humano como sujeito, o profissional da saúde deve realizar um exercício de autoconhecimento, por meio de um esforço de empatia e/ou de projeção. Porém, observa-se, em muitos destes profissionais, uma individualização que os torna alheios ao outro devido à limitação da compreensão do sujeito ${ }^{25}$.

As ações de cuidado são colocadas em prática no momento em que se transmite ou que se recebe o cuidado. Este é percebido e entendido por meio de comunicação verbal ou não- verbal, incluindo gestos, olhares, dentre outros. Qualquer ação humana só é reconhecida quando há valorização do indivíduo em qualquer contexto que se encontre ${ }^{27}$.

$\mathrm{O}$ atendimento humanizado é crucial e, muitas vezes, o retorno é gratificante. Ao receber uma resposta positiva dos pacientes e de seus familiares, percebe-se a valorização do profissional enquanto ser humano capaz de melhorar a vida do próximo ${ }^{26}$.

Os sentimentos negativos percebidos muitas vezes estão relacionados às condições de trabalho, físicas, emocionais e psicológicas, as quais os profissionais estão submetidos.

Sabe-se que a realidade do leito hospitalar em uma instituição pública difere de uma particular. É preciso uma política de recursos humanos que vise a melhoria da relação qualidade e quantidade dos profissionais do setor, objetivando uma produtividade mais adequada ${ }^{28}$. Esta produtividade é influenciada por mecanismos mais flexíveis e de motivação 29 .

A crise na saúde tem causado a diminuição da qualidade do atendimento e o aumento das filas de espera, indo contra a insaciável demanda dos consumidores por atendimento de alta qualidade ${ }^{29}$.

A própria sobrevivência do hospital depende da aprovação pelo paciente. Muitas estratégias para melhoria de serviços de saúde estão baseadas na satisfação do paciente. Ouvir e observar o comportamento dos pacientes dentro dos hospitais é fundamental para a compreensão e melhoria da organização do serviço e do ambiente hospitalar ${ }^{30}$.

Estudos acerca da humanização do profissional que atua no leito hospitalar observam um distanciamento do profissional, quando experiente, que já está "acostumado" em ter contato com a dor e o sofrimento do paciente, levando-o a agir com indiferença em relação a estes aspectos ${ }^{31}$.

A relação de ajuda é um instrumento de grande valor para que se estabeleça uma comunicação direta, esclarecedora e eficaz ${ }^{32}$.

\section{CONCLUSÃO}

Concluiu-se com este trabalho que as percepções referidas pelos estagiários-pesquisadores estão diretamente relacionadas ao impacto emocional.

Foram referenciados sentimentos de ansiedade e frustração; insegurança e incapacidade; angústia, tristeza e medo; empoderamento profissional; empatia e lembranças e; sentimentos negativos, principalmente ao contato inicial com o paciente no âmbito hospitalar.

A falta da vivência interfere na atuação do estagiário, fazendo-o buscar o apoio do docente. É pela experiência, imbuída da prática, que o estagiário adquire conhecimento técnico-prático, proporcionando uma reflexão crítica que o leva à autoconfiança.

A importância de levar o aluno ao pensamento crítico-reflexivo torna-o um profissional consciente de seu papel na sociedade, possibilitando a um atendimento mais humanizado e diferenciado implicando em uma melhora na qualidade de atendimento do paciente debilitado. 


\section{ABSTRACT}

Purpose: to build a description of perception of students-therapists of Speech, Language and Hearing Sciences in hospital bedside. Method: the research was carried out during the discipline of supervised traineeship II in Speech, Language and Hearing Sciences the semester of the Undergraduate in Speech, Language and Hearing Sciences of Fortaleza University in the period from February to June 2010. It was a qualitative approach registering the personal views of the students-therapistsresearchers by the construction of daily and field notes, in the care of neurologic patient's bedside. Results: the categories found were divided into: anxiety and frustration, insecurity and failure, anxiety, sadness and fear; professional empowerment, empathy and memories; and negative feelings. The feelings underscored the fear to intervene with the patient. However, the routine makes the trainee more secure about their procedures and, over time, it is possible to control the feelings in relation to the measures to be taken regarding the patient. Conclusion: it was concluded that the perceptions reported by trainees are directly related to the initial emotional impact. The lack of experience interferes with the performance, making the student seek the support of teachers. It is through experience that the trainee acquires techno-practical knowledge, providing a critical reflection that leads to confidence. The importance of leading the student to critical and reflective thinking makes him aware of his professional role in society, enabling a more humane and differential treatment resulting in an improved quality of weakened patient care.

KEYWORDS: Diaries; Students, Health Occupations; Speech, Language and Hearing Sciences

\section{REFERÊNCIAS}

1. Figueiredo SF, Benincasa MM. $O$ trabalho fonoaudiológico realizado à beira do leito. In: Oliveira ST. (Org). Fonoaudiologia hospitalar. São Paulo: Lovise, 2003. p. 79-108.

2. Reibnitz KS. Profissional crítico-criativa em enfermagem: a construção do espaço interseçor na relação pedagógica. Rev. Bras. Enferm. 2004;57(6):698-702.

3. Kilminster S, etal. Effective educational and clinical supervision. Med Teach., Dundee. 2007;29(1):2-19.

4. Ribeiro MMF, Amaral CFS. Medicina centrada no paciente e ensino médico: a importância do cuidado com a pessoa e o poder médico. Rev. Bras. Edu. Med. 2008;32(1):90-7.

5. Feliciano KVO, Kovacs $\mathrm{MH}$, Sarinho SW. Sentimentos de profissionais dos serviços de prontosocorro pediátrico: reflexões sobre o burnout. Rev. Bras. Saúde Mater. 2005;5(3):319-28.

6. Haidet P. Medical students attitudes toward the doctor-patient relationship. Med Educ. 2002;36(6):568-74.

7. Domingues RCL, Amaral E, Zeferino AMB. Os diferentes olhares na avaliação de alunos em estágio clínico supervisionado. Rev. Assoc. Med. Bras. 2009;55(4):458-62.

8. Batenburg V. et al. Are professional attitudes related to gender and medical specialty? Med Educ. 1999;33(7):489-92.
9. Minayo MCS. O desafio do conhecimento: pesquisa qualitativa em saúde. 10. ed. São Paulo: Hucitec, 2007.

10. Bosquetti SL, Braga ME. Reações comunicativas dos alunos de enfermagem frente ao primeiro estágio curricular. Rev. Esc. Enferm. USP. 2008;42(4):690-6.

11. Sadala MLA, Silva FM. Cuidando de pacientes em fase terminal: a perspectiva dos alunos de enfermagem. Rev. Esc. Enferm. USP. 2009;43(2):287-94.

12. Luiz ID, Damkauskas T, Ohi RIB. A importância da relação aluno-professor na vivência do exame físico de enfermagem em enfoque fenomenológico. Acta Paul. Enferm. 1997;10(3):62-72.

13. Porto AM. A morte como fator gerador de stress no centro de terapia intensiva na percepção dos alunos do $4^{\circ}$ ano do curso de fisioterapia. 2005. Tese (mestrado) - Faculdade de Ciências Médicas. Universidade Estadual de Franca, São Paulo.

14. Maio MC, Lima NT. Fórum. O desafio SUS: 20 anos do Sistema Único de Saúde. Introdução. Cad. Saúde Pública. 2009;25(7):1611-3.

15. Oliveira GF, et al. Satisfação com a vida entre profissionais da saúde: correlatos demográficos e laborais. Rev. Bioética. 2009;17(2):319-34.

16. Mota RA, Martins CGM, Véras RM. Papel dos profissionais de saúde na política de humanização hospitalar. Psicol. estud. 2006;11(2):323-30.

17. Salomé GM, Espósito VHC. Vivências de acadêmicos de enfermagem durante o cuidado 
prestado às pessoas com feridas. Rev. Bras. Enferm. 2008;61(6):822-7.

18. Valsecchi EASS, Nogueira MS. Fundamentos de enfermagem: incidentes críticos relacionados à prestação de assistência em estágio supervisionado. Rev. Latino-am. Enfermagem. 2002;10(6):819-24. 19. Benevides-Pereira AMT. Burnout: o processo de adoecer pelo trabalho. In: Benevides-Pereira AMT. (Org.). Burnout: quando o trabalho ameaça o bem estar do trabalhador. São Paulo: Casa do Psicólogo; 2002. p. 21-91.

20. Jodas DA, Haddad MCL. Síndrome de Burnout em trabalhadores de enfermagem de um pronto socorro de hospital universitário. Acta Paul. Enferm. 2009;22(2):192-7.

21. Coelho JAB, Araújo STC. Desgaste da equipe de enfermagem no centro de tratamento de queimados. Acta Paul. 2010;23(1):60-4.

22. Angerami-Camon VA. Psicologia da saúde: um novo significado para a clínica. São Paulo: Pioneira; 2000.

23. Silveira RS. Uma tentativa de humanizar a relação da equipe de enfermagem com a família de pacientes internados na UTI. Enferm. 2005; 14(4):125-30.

24. Falcon GS, Erdmann AL, Meirelles BHS. A complexidade na educação dos profissionais para o cuidado em saúde. Enferm. 2006;15(2):343-51.
25. Marcon SS, et al. Vivência e reflexões de um grupo de estudos junto às famílias que enfrentam a situação crônica de saúde. Enferm. 2005;14(4):116-24.

26. Martins MCF. Humanização das relações assistenciais de saúde: a formação do profissional de saúde. São Paulo: Casa do Psicólogo, 2001.

27. Bazotti KDV, Stumm EMF, Kirchner RM. Ser cuidada por profissionais da saúde: percepções e sentimentos de mulheres que sofreram abortamento. Enferm. Florianópolis. 2009;18(1):147-54.

28. Zucchi $P$, Bittar OJNV. Funcionários por leito: estudo em alguns hospitais públicos e privados. Rev. Adm. Saúde. 2002;4(14):65-76.

29. Bittar OJNV. Política de recursos humanos em hospitais. Revista de Administração da USP. 1996;31(1):91-6.

30. Kotaka F, Pacheco RLM, Higaki Y. Avaliação pelos usuários dos hospitais participantes do programa de qualidade hospitalar no Estado de São Paulo, Brasil. Rev. Saúde Pública. 1997;31(2):171-7. 31. Crepaldi MA. Bioética e interdisciplinaridade: direitos de pacientes e acompanhantes na Hospitalização. Paidéia (Ribeirão Preto). 1999;9(16):89-94.

32. Ramos TMB, Pedrão LJ, Furegato ARF. A relação de ajuda não-diretiva junto ao cuidador de um idoso incapacitado. Rev. Eletr. Enf. 2009;11(4):923-31.
http://dx.doi.org/10.1590/S1516-18462012005000082

RECEBIDO EM: 08/04/2011

ACEITO EM: 05/08/2011

Endereço para correspondência

Moisés Andrade dos Santos de Queiroz

Rua 1044, 16, Conjunto Ceará

Fortaleza - CE

CEP: $60532-820$

E-mail: moisesandrade@live.com 